\title{
O ENCONTRO DE FRACASTORO COM DESCARTES: REFLEXÃO SOBRE A TEMPORALIDADE DO MÉTODO
}

\author{
Luiz Alberto Peregrino Ferreira1, Flávia Regina Ramos², Selvino Assmann ${ }^{3}$
}

\footnotetext{
${ }^{1}$ Doutor em Enfermagem. Professor do Departamento de Análises Clínicas do Centro de Ciências da Saúde da Universidade Federal de Santa Catarina (UFSC). Santa Catarina, Brasil. E-mail: lulaperegrino@ccs.ufsc.br

${ }^{2}$ Doutora em Filosofia da Enfermagem. Professora do Departamento de Enfermagem e do Programa de Pós-Graduação em Enfermagem da UFSC. Pesquisadora do CNPq. Santa Catarina, Brasil. E-mail: flavia@nfr.ufsc.br

${ }^{3}$ Doutor em Filosofia. Professor do Departamento de Filosofia da UFSC. Santa Catarina, Brasil. E-mail: selvinoa@terra.com.br
}

RESUMO: O objetivo é o de demonstrar a importância do método na prática cientifica a partir da emergência da ciência moderna e seu modelo de racionalidade. Trata-se de uma reflexão filosófica, uma aproximação imaginária por cartas, entre Fracastoro e Descartes, estas fundamentadas em bibliografias encontradas no LILACS, SciELO e buscador Google. Os autores utilizaram a descrição por meio de cartas de um contato fictício entre Girolamo Fracastoro e René Descartes. O primeiro, a partir de suas obras Syphilis Sive Morbus Gallicus e De contagione et contagiosis morbis et curatione; o segundo com o Discurso do Método, utilizado como modelo da ciência moderna e Regras para a Direção do Espírito. A aproximação imaginada pelos autores, entre Fracastoro e Descartes revela que o método proposto por Descartes, se houvesse sido utilizado pelo cientista italiano, abriria novas possibilidades de visibilidade e ressonância de sua obra.

DESCRITORES: História. Filosofia. Saúde.

\section{THE MEETING OF FRACASTORO WITH DESCARTES: REFLECTION ON THE TEMPORALITY OF THE METHOD}

\begin{abstract}
The objective of this study is to demonstrate the importance of the scientific method since the emergence of modern science and its model of rationality. It is a Philosophical reflection by means of an imaginary approximation of letters between Fracastoro and Descartes, based on bibliographies found in LILACS, SciELO, and the Google search engine. The authors used descriptions by means of letters from a fictional correspondence between Girolamo Fracastoro and René Descartes. The former, from his works Syphilis Sive Morbus Gallicus and De contagione et contagiosis et curatione and the latter with the Speech of the Method, used as a model of modern science and Rules for the Direction of the Spirit. The approach supposed by the authors between Fracastoro and Descartes reveals to us that the method proposed by Descartes, if it had been used by the Italian scientist, would have opened new possibilities of visibility and projection of his works.
\end{abstract}

DESCRIPTORS: History. Philosophy. Health.

\section{LA REUNIÓN DE FRACASTORO CON DESCARTES: REFLEXIONES SOBRE LA TEMPORALIDAD DEL MÉTODO}

RESUMEN: El objetivo es demostrar la importancia del método en la práctica científica a partir de la emergencia de la ciencia moderna y su modelo de racionalidad. Se trata de una reflexión filosófica, una aproximación imaginaria mediante cartas entre Fracastoro y Descartes, siendo fundamentadas a través de las bibliografías encontradas en LILACS, SciELO y el buscador Google. Los autores utilizaron la descripción por medio de cartas de un contacto ficticio entre Girolamo Fracastoro y René Descartes. El primero, a partir de sus obras Syphilis Sive Morbus Gallicus y De contagione et contagiosis morbis et curatione, y el segundo con el Discurso del Método, obra utilizada como modelo de la ciencia moderna, y Reglas para la Dirección del Espíritu. La aproximación imaginada por los autores, entre Fracastoro y Descartes nos revela que el método propuesto por Descartes, si hubiese sido utilizado por el científico italiano, abriría nuevas posibilidades de visibilidad y proyección de la obra de su autoría.

DESCRIPTORES: Historia. Filosofía. Salud. 


\section{INTRODUÇÃO}

O texto aqui apresentado teve como ponto de partida o interesse suscitado pela obra de Girolamo Fracastoro (1478 ou 1479-1553), que surgiu durante as disciplinas de Filosofia da Ciência e da Saúde e em estudo independente sobre a historicidade das infecções, integrante do Curso de Doutorado, Programa de Pós-Graduação em Enfermagem, do Centro de Ciências da Saúde da Universidade Federal de Santa Catarina. Foi realizada uma aproximação entre Girolamo Fracastoro, médico e humanista italiano que adotou a arte da poesia para escrever seu trabalho sobre a sífilis e René Descartes (1596-1650) advogado, matemático e pensador francês que apresentou o método como norteador do conhecimento científico.

Para efetuar esta aproximação e o confronto entre duas figuras importantes da história da ciência, imaginamos e apresentamos uma sequência de cartas fictícias trocadas entre eles. Esse recurso literário inspirou-se também em dois fatos: o de Fracastoro ter recorrido ao poema para apresentar, há mais de 400 anos, a sua obra sobre a sífilis e a publicação, em 1546, do conceito de contágio e as formas de transmissão das doenças. Mesmo que não tenham sido contemporâneos, o médico e humanista italiano, e o advogado, matemático e filósofo francês foram decisivos para a formulação do método científico, o que permitia solidez e consistência aos conhecimentos, e, contemporaneamente, inaugurou uma nova atitude humana frente à natureza.

\section{Girolamo Fracastoro}

Girolamo Fracastoro nasceu em Verona. Alguns autores citam como ano do seu nascimento o de 1478 e outros, o ano de 1479. Em 1530 publicou seu poema com 1300 versos intitulado Syphilis Sive Morbus Gallicus, nos quais descreveu uma doença que assolava o mundo, a sífilis. Em 1542 foi nomeado médico do Concílio de Trento. ${ }^{5}$ Em 1546, publicou o livro De contagione et contagiosis morbis et curatione, onde definiu o contágio como causa das infecções e classificou a doença de acordo com três modos de transmissão, por contato direto, por intermédio de fômites ou à distância. Um ano antes de morrer, publicou três diálogos filosóficos: Naugerius sive de Poética, Turrius sive de Intellectione e Fracastorius sive de Anima. Morreu em Verona em 1553..$^{6-11}$

\section{René Descartes}

Nasceu em 31 de março de 1596 em Turena, na França. Graduou-se em Direito, no ano de 1616.
Em 1637 publicou o Discurso do Método e teve a sua obra escrita em latim e as Regras para a Direção do Espírito, foram publicadas somente depois de sua morte. Faleceu em 11 de fevereiro de 1650. ${ }^{4,9}$

O trabalho tem como objetivo demonstrar a importância do método na prática científica a partir da emergência da ciência moderna e seu modelo de racionalidade e caracteriza-se como uma reflexão embasada em busca documental e bibliográfica.

\section{METODOLOGIA}

Desenvolvemos uma busca do material bibliográfico de modo a obter fundamentos para a sistematização das cartas, sendo estas por sua vez inspiradas nas Cartas de São Paulo no Novo Testamento. ${ }^{1}$ Com a finalidade de orientar, no tempo e a forma para leitura, destacamos os fatos principais que definem seus conteúdos e oferecemos uma orientação acerca da comunicação imaginária entre os dois autores. ${ }^{2-3}$ Fracastoro envia uma primeira carta para Descartes, na qual descreve um sonho que havia tido; cita algumas doenças, com ênfase na sífilis. Descartes responde enunciando o primeiro princípio do Discurso do Método, apoiado pelas Regras para a Direção do Espírito, de números 1 a 4. A partir destas cartas, Fracastoro escreve sobre seus trabalhos e Descartes continuou orientando-o com outros princípios do Método, sempre apoiado pelas demais Regras para a Direção do Espírito.

Na última carta de Fracastoro, ele descreve sua dedicação à ciência, agradece ao amigo Descartes todos seus ensinamentos e o que espera do futuro. Em nossa imaginação, a carta nunca chegou ao seu destino. Descartes, nunca mais soube do amigo e não respondeu à última carta de Fracastoro. Na vida real, Descartes não concluiu as regras.

Procuramos por artigos de periódicos, utilizando o termo infecções, como palavra-chave e assunto. A fonte de busca inicial foi a Literatura Latino-Americana e do Caribe em Ciências da Saúde (LILACS) onde as informações estão registradas a partir do ano de 1982 e o Scientific Electronic Library Online (SciELO). Além disso, consultamos as mesmas bases de dados e o buscador Google, utilizando nome do cientista italiano como palavra chave. Acerca de Descartes, adotamos o Discurso do Método e as Regras para a Direção do Espírito. ${ }^{4}$

A partir das informações documentais, os autores criaram as cartas, que foram utilizadas como instrumento, no qual apresentam a reflexão 
e ilustram o contexto da época, sobre os métodos científicos utilizados por Fracastoro e Descartes.

\section{REFLEXÃO SOBRE O MÉTODO E O CON- TÁGIO. UM DIÁLOGO POR INTERMÉ- DIO DE CARTAS}

\section{Carta 1 de Girolamo Fracastoro para René Descartes}

Senhor Descartes:

Recentemente tive um sonho terrível sobre o fim da humanidade. O Mundo vivia assolado pelas pestes, pela lepra, pela tisis, pela raiva, varíola e tifo. Não bastasse tudo isto, surge uma nova enfermidade, morbus gallicus, que quando não mata, deixa loucos os sobreviventes.

Acordei-me sobressaltado, ainda absorto com meus sonhos, ou pesadelos e passei a meditar sobre as enfermidades que têm assolado a humanidade.

Veja a peste. Desde que chegou a Roma, no século II a.C., devastou a população da bacia do Mediterrâneo, foi para Veneza, Londres, Gênova, por todo o Continente.

E a Lepra. No rastro das Cruzadas, o Ocidente foi tomado por este mal, já citado no Antigo Testamento, em Levítico. Enfermidade enigmática, que devido aos tubérculos pode deixar o enfermo com aparência de leão e por isso chamada leonina, ou que altera a pele do doente, que fica parecendo pele de elefante e por isso também chamada elefantíase.

Não podemos esquecer a "praga antonina", atualmente denominada varíola, que afetou nosso Continente com o retorno dos cruzados. Parece que os servos do cristianismo carregam consigo "uma espécie de pecado".

Veja o morbus gallicus, enfermidade trazida por Colombo, do Novo Continente e transmitida pelos franceses aos italianos.

Como pode ver as enfermidades que citei, entre tantas outras, parecem nos seguir por toda nossa história. Porém, em cada tempo, mais e mais pessoas morrem, algumas vezes em episódios curtos na qual logo morrem muitos ou, como em outras vezes morrem de forma silenciosa, porém não menos cruel.

Prezado Senhor, desculpa-me por tão longa carta. Mas, tenho sonhos que, a exemplo dos seus sonhos, vindos só do alto, tanto me atormentavam que eu preferi lhe escrever, para salvá-los do si- lêncio e mesmo que não estejam descritos como uma obra, tento salvá-los do esquecimento, para o bem da humanidade

Verona, 18 de maio de 1525.

Hieronymus Fracastoro - Philosophus, Medicus, Poeta, Astrologus eminentissimus.

\section{Carta 1 de René Descartes para Girolamo Fracastoro}

Senhor Hieronymus:

Permita-me tratá-lo como amigo, uma vez que nossos sonhos e talvez nossas almas tenham inquietações semelhantes.

Muito boa a descrição dos seus sonhos, que com certeza serão obra para a humanidade.

Também aprendi com meus sonhos e digo: não se deve aceitar como verdadeira nenhuma coisa que não se conheça como tal, isto é, evitar, com todo o cuidado, a precipitação e a prevenção e só incluir em nossos juízos o que se apresentar de modo tão claro e distinto ao espírito, que não se tenha ocasião alguma para dele duvidar. ${ }^{4}$

Os homens costumam, sempre que descobrem alguma semelhança entre duas coisas, atribuir a ambas, mesmo naquilo em que são diversas, o que de uma delas reconhecem como verdadeiro. ${ }^{4}$

Isto eu aprendi ainda quando jovem, ao estudar lógica e a análise dos geômetras. As instruções da lógica servem muito para explicar as coisas que já se sabe e, para o entendimento da análise dos geômetras, é necessária a fadiga da imaginação. ${ }^{4}$

Uma grande capacidade de dedução foi demonstrada em sua carta e por isso o considero um observador. Conhece vários fatos semelhantes e que talvez, entre eles, possa existir algo em comum, mas necessita refletir sobre algumas deduções.

Sua intuição revela um espírito atento, que nasce da luz da razão e, por ser mais simples, é mais certo do que a sua dedução. Sua intuição e sua dedução podem levá-lo ao encontro da verdade.

Portanto, torna-se imprescindível que haja um método para a realização de qualquer estudo.

Por último quero escrever que não concordo com a culpa atribuída aos franceses na doença denominada Mal Francês. Penso ser Colombo e sua tripulação os responsáveis por trazer ao nosso Continente a terrível doença. 
Ainda há muito para refletirmos. Por ora termino aqui.

Que Deus esteja contigo.

La Haye, 18 de dezembro de 1525

René Descartes

Pensador, Filósofo, Servo de Deus.

\section{Carta 2 de Girolamo Fracastoro para René Descartes}

Senhor Descartes:

Volto a lhe escrever, já na condição aceita de amigo, para apresentar-lhe o meu pensar sobre as enfermidades.

Vou escrever primeiro sobre o morbus gallicus, sobre a qual tenho concentrado meus trabalhos. Vários motivos levaram-me a isto, em atenção às suas recomendações, na busca da verdade, com intuição e dedução sobre os fatos. Tenho certeza que a doença não foi trazida por Colombo. Espalhou-se pela Europa por mercenários que lutaram na guerra entre Alfonso II de Nápoles e Carlos VIII da França. À Nápoles primeiro veio e somente da França tomou seu nome. Dali foi para Alemanha, França, Suíça, Holanda, Grécia, Inglaterra, Escócia, Hungria e Rússia. O mal também correu pela costa da Ásia e da Líbia. ${ }^{12}$

Deduzi que a enfermidade é transmitida pelo sexo e se espalha por meio de sementes invisíveis, que podem se reproduzir sozinhas. Entre a entrada das sementes em cada novo indivíduo e o aparecimento dos sintomas, leva poucos dias. O local de entrada das sementes fica marcado por uma ferida, são as sementes se reproduzindo. Fiz a descrição da doença em versos, na obra publicada em 1530 e intitulada Syphilis Sive Morbus Gallicus, na qual conto as desventuras de Syphilus, um pastor, que desafiou o Deus Sol, em favor do Rei Alcítoo e por isso foi o primeiro a ser punido com as pústulas da doença. ${ }^{6}$ Foi, portanto, a origem de tudo, doença que chamo de sífilis e não mais de mal francês.

Entendo o meu trabalho como uma dádiva de Deus. Não posso esquecer sem dúvida dos amigos, como você, ou como o Cardeal Pietro Bembo, que me auxiliou muito na escrita dos livros. ${ }^{9}$

Entretanto, devo admitir que, continuo preocupado com as outras enfermidades, para tentar descobrir logo o que com elas acontece. Minha intuição me leva a pensá-las como uma coisa só, porém, minha razão não consegue entendê-las desta forma.

É um grande prazer poder comentar meu pensar sobre as enfermidades. Reconheço que o dileto amigo muito tem me ajudado a construir tudo que apresentei.

Incaffi, 15 de janeiro de 1531.

Hieronymus Fracastoro - Philosophus, Medicus, Poeta, Astrologus eminentissimus.

Seu amigo.

\section{Carta 2 de René Descartes para Girolamo Fracastoro}

Senhor Hieronymus:

Fico feliz ao saber que sua intuição e sua dedução o levaram por bons caminhos. Não me refiro à troca do nome da enfermidade (agora sífilis), gentileza que agradeço, mas às descobertas por você realizadas, definindo muito bem o fruto do seu conhecimento, da sua observação, a verdade.

Por outro lado percebo que ainda existe em você uma grande angústia, devido às outras enfermidades.

Por isso lhe digo que para resolvê-las deve dividir cada uma das coisas que deseja examinar em tantas partes quanto possível e necessário para resolvê-las. ${ }^{4}$

Para uso de um método há necessidade de ordem e disposição dessas coisas e para elas deve dirigir toda a agudeza do seu espírito.

Veja o que você já conseguiu com a sífilis!

Procure reduzir gradualmente as proposições complicadas e obscuras a outras mais simples. ${ }^{4}$ Depois, a partir destas deixe sua intuição e sua dedução guiarem você, como se fora o fio de Teseu no labirinto.

Mas lembre-se, antes será necessário distinguir as coisas mais simples daquelas mais complicadas, para poder seguir ordenadamente no seu trabalho.

Entretanto, todas as coisas - quando não consideramos suas naturezas isoladamente, mas as comparamos entre si a fim de que se possam conhecer umas pelas outras - podem ser classificadas em absolutas ou relativas. ${ }^{4}$

Chamo absoluto ao que contém em si a natureza pura e simples de que se trata uma questão, como por exemplo, "causa". Relativo é o que participa desta mesma natureza ou, pelo menos, em alguma coisa dela, pelo qual pode ser referido ao absoluto e deduzir-se dele conforme certa ordem, mas, além disso, envolve em seu conceito algumas outras coisas que chamo relações. Assim o "efeito" pode ser relativo. ${ }^{4}$ 
Para o estudo das enfermidades, sugiro ainda que as estude com movimento contínuo da sua imaginação, vendo intuitivamente cada uma em particular enquanto vai passando às outras.

Percorra a cadeia de informações e as conclusões que vai obter, porque assim poderá deduzir cada coisa em seu tempo, seu espaço, seu lugar e distinguir as coisas entre si. Na série de coisas a investigar caso alguma delas se apresentar de forma que o seu entendimento não possa intuir suficientemente bem, será preciso deter-se ali, sem examinar as demais que se seguem, evitando assim um trabalho supérfluo. ${ }^{4}$

Aplique o seu espírito no conhecimento das enfermidades e encontrará a verdade: ou chegará completamente até ela ou verá que depende de alguma experiência que não está no seu poder e então o que buscas pode transpassar totalmente os limites da inteligência humana, ou pelo menos da nossa.

Siga seus desígnios traçados por Deus, a quem peço que lhe abençoe e continue lhe conduzindo no caminho da verdade sobre as enfermidades que assolam a humanidade.

La Haye, 20 de outubro de 1532.

René Descartes - Pensador, filósofo e amigo.

\section{Carta 3 de René Descartes para Girolamo Fracastoro}

Amigo Hieronymus:

Há muito tempo não tenho notícias de você, porém já posso lhe contar os reflexos dos seus estudos com a sífilis. Os banhos coletivos estão sendo substituídos por outras terapias, nas quais o uso de essências perfumadas é a principal característica.

A alopécia e as úlceras no pescoço, decorrentes da sífilis em seu estágio mais avançado, estão fazendo surgir novos costumes, como o uso das cabeleiras postiças e das rendas farfalhudas e outros adereços no pescoço, presentes em todas as cortes espalhadas pelo nosso Continente. Tudo para tentar esconder os sinais da doença.

Quanto à prostituição, finalmente passou a ser perseguida. Por outro lado, algumas pessoas têm utilizado intestino de porco para a realização do sexo, acreditando que isto possa evitar a doença. Coitados, terão partes de animais em seus corpos.

A preocupação com a enfermidade conduziu a igreja a incorporar mais um santo de urgência: São Dionísio é agora o patrono dos sifilíticos.
Como não tenho recebido notícias do amigo, vou continuar escrevendo, na esperança de poder ajudar-lhe.

Digo que deve conduzir por ordem os seus pensamentos, iniciando pelos objetos mais simples e mais fáceis de conhecer, para chegar, aos poucos, gradativamente, ao conhecimento dos mais compostos e, supondo também, naturalmente, uma ordem de precedência de uns em relação aos outros. ${ }^{4}$

É necessário desenvolver ao mesmo tempo, as duas faculdades principais do nosso espírito, a saber: a perspicácia, tendo a intuição clara de cada coisa e a sagacidade, deduzindo habilmente umas de outras.

Conhecemos como se deve usar a intuição pela comparação com os nossos olhos, pois o que quer ver, muitos objetos de uma vez não verá nenhum deles distintamente e igualmente. Ao que quer atender a muitas coisas a um só tempo com um só ato e pensamento ficará com o espírito confuso. Assim, para que o espírito se torne sagaz, deve exercitar-se em investigar as mesmas coisas que já foram encontradas por outros e em percorrer com método todos os menos importantes artifícios dos homens e, sobretudo, aqueles que manifestam ou supõem. ${ }^{4}$

Depois da intuição de algumas proposições simples, se delas tirarmos outra conclusão, é útil percorrê-las por meio de um movimento contínuo do pensamento e em nenhum lado interrompido, refletir sobre suas mútuas relações e, fazendo todo o possível, conceber distintamente várias coisas ao mesmo tempo; pois é assim que nosso conhecimento se torna muito mais certo e é aumentada a capacidade do espírito. ${ }^{4}$

É preciso utilizar todos os recursos do entendimento, da imaginação, dos sentidos e da memória, tanto para termos uma intuição distinta das proposições simples, quanto para estabelecermos, entre as coisas procuradas e as coisas conhecidas, uma ligação adequada que as permita reconhecer, como também para encontrar as coisas as quais devem ser comparadas entre si, para que não se omita nenhum recurso dos que estão ao alcance dos homens.

Desculpe-me amigo pela carta tão longa. É que depois de tanto tempo, sem contato com você, decidi escrever tudo sobre o que tenho trabalhado. No que diz respeito ao conhecimento, duas coisas são necessárias ter em conta, a saber, nós e o que conhecemos e as coisas a conhecer. Só o entendimento é capaz de perceber a verdade, 
mas este deve ser ajudado pela imaginação, os sentidos e a memória.

Que a paz do Senhor reine junto a você.

Paris, 12 de junho de 1539.

René Descartes - Pensador, Filósofo e seu amigo.

\section{Carta 3 de Girolamo Fracastoro para René Descartes}

Senhor Descartes:

Espero que ao final desta você, meu amigo, possa entender minha demora em responder.

Tenho seguido seus conselhos para conduzir em ordem meus pensamentos. Também procurei o absoluto e o relativo e, devo dizer, encontrei a relação de causa e efeito, encontrando, com auxílio da minha intuição e da minha dedução, as coisas simples nas enfermidades que assolam a humanidade.

Fui ler Demócrito, quando postulou que havia partículas que podiam passar de enfermos para pessoas sadias, fui ler Galeno e Varro, que metaforicamente descreviam sementes de doenças e reparei qual o efeito de uma fruta podre sobre uma sã.

Publiquei no início de 1546 o livro De contagione et contagiosis morbis et curatione, onde pela primeira vez foram descritas as enfermidades que podem classificar-se como contagiosas, incluindo a peste, a lepra, a tisis, a sarna, a raiva, a erisipela, a varíola, o antrax e o tracoma. Incluí ainda, como contagiosas, o tifo exantemático e a sífilis. ${ }^{9,11}$

Estabeleci o conceito de contágio e propus como acontece a transmissão das doenças, na qual seminaria contaginum - sementes de contágio - são transmitidas de indivíduos doentes para outros sadios. Esta transmissão pode ocorrer por uma de três formas: por contato direto entre pessoas, por meio de fômites-objetos, ou à distância, sem contato direto, pelo ar e sem a presença de qualquer força oculta. No total foram três livros escritos, o primeiro tratando do mecanismo de contágio, o segundo detalhando cada doença e as classificando de acordo com o modo de transmissão e no terceiro descrevi o tratamento. ${ }^{9}$

Agora posso dizer que as sementes constituem a causa de uma infecção e o alastramento é o efeito. Está estabelecida a ligação entre o absoluto e o relativo, do mesmo modo que o contágio está ligado às infecções.

Aliás, escrevi também um trabalho intitulado De Sympathia et antipathia rerum, no qual apre- sento a base filosófica para meus estudos sobre as doenças contagiosas. Nele me ponho contra as doutrinas mágico-esotéricas segundo as quais todas as doenças são explicáveis pela influência de seres imateriais, fora do nosso universo. Ora, as causas das doenças não podem ser imateriais. Há, sim, no próprio universo regras bem precisas e infalíveis. E neste universo há coisas que se atraem e outras que se repelem; há simpatias e antipatias, que fazem com que sementes se reproduzam ou não, contagiem ou não corpos receptores e é com base nisso que se pode chegar a entender melhor e a enfrentar as doenças. ${ }^{9}$

Desejo ainda que continue me ensinando os caminhos de busca da verdade sobre as enfermidades e me dando a direção ao meu espírito.

Incaffi, 15 de junho de 1547.

Hieronymus Fracastoro - Philosophus, Medicus, Poeta, Astrologus eminentissimus.

Seu amigo.

\section{Carta 4 de René Descartes para Girolamo Fracastoro}

Amigo Hieronymus:

Fico satisfeito com as suas descobertas. Creio que começaram a ser desvendados os mistérios das enfermidades, o que poderá mudar tudo o que se conhece sobre as elas. Isto sim é uma dádiva de Deus, que permanecerá eternamente para a humanidade. Lembra dos seus sonhos e do que você falava sobre eles?

Pois bem, muito temos a dizer na continuidade da discussão de um método, como se deve fazer, para cada caso, enumerações tão completas e revisões tão gerais até que haja a certeza de nada ter omitido. Quanto aos homens, saiba que a diversidade de opiniões não provém do fato de uns serem mais racionais do que outros, mas tão somente em conduzirem o pensamento por diferentes caminhos. ${ }^{4}$

Não basta ter o espírito bom, o essencial é aplicá-lo bem. ${ }^{4}$

Mostrar nosso trabalho ao público é importante para resolver a breve duração da vida e a falta de experiência. Assim, daqui para frente cada ser humano, segundo sua própria inclinação e poder, irá contribuir para as experiências que forem necessárias realizar, comunicando por sua vez ao público tudo o que aprendeu, para que os últimos comecem onde os seus antecessores acabaram e, reunindo assim as vidas e os trabalhos de muitos, 
poderemos ir, juntos, muito mais longe do que cada um em particular.

Meu amigo, que nos seus caminhos você sempre encontre a verdade.

Amsterdã, 12 de junho de 1550.

René Descartes - Pensador, Filósofo e seu amigo.

\section{Carta 4 de Girolamo Fracastoro para René Descartes}

Meu Grande Amigo Descartes:

Poucos têm o privilégio de conhecer pessoas como você. Mesmo que publiquemos todos nossos trabalhos, nossos íntimos jamais estarão nas escritas, viverão sempre no espírito e na alma de cada um. Nossa troca de correspondências aproximou, também, nossos espíritos.

Mas, vamos a alguns fatos de trabalhos que não conclui e por isso não posso ainda publicá-los.

No último tratado de astronomia, pude usar um conjunto de lentes sobrepostas, que permitiu uma visualização melhor dos planetas. A lua meu amigo, estava ao alcance das minhas mãos. Com ele creio que será possível ver as sementes, causadoras das enfermidades e assim descobrir do que são feitas. ${ }^{9}$

Gostaria de lhe contar, que parte da minha vida dediquei ao estudo das enfermidades, e tive muita ajuda sua sobre os ensinamentos e as condutas de um método. Só não escrevo o que porventura deixei de ver, ou aquilo que meus olhos não puderam ver, ou que não existia em minha mente. Mas, tenho certeza, que outros virão, para continuar de onde parei, visualizarão o que não pude, terão mentes mais privilegiadas que a minha e poderão descrever o que não consegui.

Por exemplo, espero que as sementes causadoras das enfermidades sejam verdadeiramente identificadas e conhecidas, além de onde meus olhos vêem e minha intuição me diz e que causa e efeito sejam considerados como método ou regra para a melhor compreensão das doenças.

Meus escritos sobre as enfermidades poderão salvar a humanidade do seu fim, aquele que me foi descrito pelo alto no meu sonho. Tomara que estes nossos escritos sobrevivam por muito tempo.

Quem sabe se alguma vez nossos netos ao lêlos e conhecerem os sinais e as faces da peste, achem neles uma grande ajuda. Porque com o correr dos anos, haverá de novo um tempo, quando assim o disponha o destino, em que esta doença jazerá ador- mecida numa noite escura, como entregue à morte, para, após longos séculos resurgir e voltar. ${ }^{13}$

Que Deus nos abençoe.

Incaffi, 15 de fevereiro de 1553.

Hieronymus Fracastoro - Seu amigo.

\section{CONSIDERAÇÕES FINAIS}

Girolamo Fracastoro foi um cientista que descreveu detalhes de doenças e sua transmissão, comprovados somente alguns séculos depois, adotando para tanto a observação, o entendimento, a imaginação, a intuição e a dedução. Possuía a prática, sem conhecer os fundamentos do método. Mas, desde sua época, a prática da busca do conhecimento não deixava de ser determinada pela intuição, ou com base em procedimentos que, se não expressavam o caminho unívoco e rigoroso para o saber legítimo, claro e distinto (método cartesiano), não prescindiam de uma lógica de transposição da experiência subjetiva da descoberta e reflexão para o conhecimento público e aplicável.

Para Fracastoro, pensar era idêntico a empenhar-se para encontrar. Para saber mais, era necessário investigar tudo que estava relacionado a um objeto parcialmente conhecido e presente em uma questão. Esta investigação devia ser realizada em duas etapas, a da resolução e a da composição, ou a da análise e a da síntese, imitando a natureza, decompondo coisas em seus elementos constitutivos e os recompondo para reformar o todo. ${ }^{14}$

Os fundamentos desta forma de investigar foram descritos, em outra época e contexto, por Descartes em seus trabalhos - O Método e As Regras para a Direção do Espírito. Nestes trabalhos apresentou os preceitos que deveriam ser utilizados para bem conduzir a razão na busca da verdade dentro da ciência. ${ }^{4}$

As idéias claras e distintas, a intuição, a dedução, a busca da causa quando observado um efeito, foram elementos propostos e sistematizados por Descartes. Isto foi praticado por Fracastoro, sem que o mesmo denominasse de método. Assim, ressalta-se que o método não substitui o pensamento, mas lhe fornece direcionalidade e lhe atribui valor no contexto coletivo de sua exposição e justificação, ou seja, comprovação e refutação.

\section{REFERÊNCIAS}

1. Cartas de São Paulo. In: Bíblia Sagrada. São Paulo: Sociedade Bíblica Internacional; Edições Paulinas (SP); 1990. Edição Pastoral. p.1437-535. 
2. Caregnato RCA, Mutti R. Pesquisa qualitativa: análise de discurso versus análise de conteúdo. Texto Contexto Enferm. 2006 Out-Dez;15(4):679-84.

3. Padilha MICS, Borenstein MS. O método de pesquisa histórica na enfermagem. Texto Contexto Enferm. 2005 Out-Dez;14(4):575-84.

4. Descartes R. Discurso do Método: regras para a direção do espírito. São Paulo (SP): Martin Claret; 2003.

5. Pozo A. Texto integro del Concilio de Trento. [acesso 2005 Jun 06]. Disponível em: http:// www.personal. us.es/alporu/histsevilla/concilio_trento.htm.

6. López-Moreno S, Garrido-Latorre F, HernándezAvila M. Desarrollo histórico de la epidemiología: su formación como disciplina científica. Salud Pública Méx. 2000;42(2):133-43.

7. Hudson MM, Morton RS. Fracastoro and syphilis: 500 years on. Lancet. 1996;348:1495-6.

8. Thyresson N. Girolamo Fracastoro and syphilis. Int J Dermatol. 1995;34(10):735-9.

9. Daglio P. Da Fracastoro a Pasteur: le concezioni sulle malattie infettive da rinascimento all'era microbiologica. Minerva Med.1969; 60:3797-817.

10. BlockSS. Historical Review. In: BlockSS. Disinfection, sterilization and preservation. Philadelphia (USA): Lippincontt Williams\& Wilkins; 2000. p. 4-17.

11. Longo LD. Syphilis sive morbus gallicus. Am J Obstet Gynecol. 1978; 15:497-8.

12. Lederberg J. History science. Infectious. 2000; 288:287-93.

13. Fracastorii, H. Syphilis sive Morbus Gallicus. Londini, 1720. [acesso 2006 Dez 14]. Disponível em: http://galenet.galegroup.com/servlet/ECCO?d5= $\mathrm{d} 7 \& \mathrm{~d} 7=1 \& \mathrm{~d} 6=32 \& \mathrm{dd}=0 \& \mathrm{vrsn}=1.0 \&$ locID $=$ capes 49 $\& d 1=0275200100 \& b 1=K E \& s r c h t p=b \& c=6 \& S U=A 1$ $1 \& \mathrm{~d} 4=0.5 \&$ stp $=$ Author $\& \mathrm{n}=10 \& \mathrm{~b} 0=$ FRACASTORO $\&$ stp $=$ Author $\& \mathrm{~d} 3=32 \& \mathrm{~d} 4=0.5 \& \mathrm{dd}=0 \& \mathrm{ste}=10 \& \mathrm{doc}$ Num $=$ CW3307445381\&df $=\mathrm{f}$

14. Crescini A. Il metodo analítico nella scuola di Padova. In: Crescini A. Le origini del metodo analitico: il cinquecento. Udine (IT): Del Bianco; 1965. p. 187-95. (Università degli Studi di Trieste. Facoltà di Lettere e Filosofia. Instituto di Filosofia).
Correspondência: Luiz Alberto Peregrino Ferreira Departamento de Análises Clínicas, Centro de Ciências da Saúde/UFSC.

Campus Universitário, Trindade, 88040-900 - Florianópolis, SC, Brasil E-mail: lulaperegrino@ccs.ufsc.br
Recebido em: 16 de março de 2009 Aprovação final: 7 de dezembro de 2009 